\title{
The Role of Exhibitions in the Marketing Mix in South Africa
}

\section{S McCoy}

Strategy and Business Development, KSDP, Johannesburg

\section{P J du Plessis}

Department of Marketing and Communication Management, University of Pretoria

\section{ABSTRACT}

Exhibitions are a recognised component of a company's marketing mix. The medium however suffers from a distinct lack of integration and understanding in the broad marketing fraternity. Little research on the subject has been done and published, especially in South Africa. This exploratory study focuses on the use of the exhibition medium as a part of a company's marketing effort. Respondents question the return on investment and the measurability of the medium, while the benefits are in agreement with other published literature. Future research on the effectiveness of the medium and the impact of technology is recommended, as well as the viability of the medium on the marketing of services.

JEL M31

\section{INTRODUCTION}

Exhibitions have been used as a marketing medium throughout the world for more than a century. Due to their cost-effectiveness, they are an integral part of the marketing mix of companies. This tool is increasingly being used to penetrate new markets as a powerful sales, marketing and general business platform.

In the South African context, trade exhibitions have formed part of marketing for more than 30 years. They have displayed exponential growth with the new political dispensation and reintegration into the global economy. Notwithstanding this accelerated growth, it is evident that in many cases the real potential of the medium is not being recognised and it is either poorly or underutilised in terms of integration with other aspects of the marketing mix or a company's business objectives generally (De Wet, 1997). 


\section{Conceptual framework}

An important picture is emerging in the broader media sector, of which exhibitions are an important part. Although this deviates slightly from the core focus of this exploratory study, it is regarded as fundamentally important to the future of exhibitions as a tool in the marketing mix.

Schutte and Jack (1997) refer to the definition of media as a communications platform. This is subdivided into entertainment-based and non-entertainment media. The emergence of narrowcast media in an environment of audience fragmentation is highlighted. Narrowcast media is defined as targeted media that can deliver to advertisers, clearly defined interest groups and/or demographics. The examples of radio, specialist publishing, direct marketing and specialist marketing are used. The nature of the group excluded the exhibition medium, but it is clear that exhibitions do fit into this brief and form an integral part of the findings.

Another important aspect of the research is the postulation of the ICE age, which is defined as the integration of the Information, Communication and Entertainment industries. In this context, numerous references are cited that highlight the total lack of integration, or the need to further integrate marketing communication options in an attempt to enhance the performance of the medium. These research findings are supported by a PriceWaterhouseCoopers survey (Finance Week, 1999) in which the TICE model is presented, representing the integration of Technology, Information, Communication and Entertainment.

There can be little doubt that the media industry has experienced prolific developments and options in recent years. Exhibitions represent a stable, unique and dynamic marketing communications tool and could prove to be significantly more effective if integrated into mainstream marketing thinking.

Because of the fragmented approach to exhibitions in the South African marketing mix so far, marketing circles question whether exhibitions are efficient and yield good return on investment.

International experience seems to contradict the South African trend. In many leading market economies, exhibitions play a fundamental role in marketing and are regarded as crucial tools for stimulating trade in specific industries and even between countries. Accordingly, they occupy a larger proportion of the marketing budget and are integrated into the marketing strategies and activities of several leading corporations. 
Exhibitions fit into the marketing communication mix as part of sales promotion activities. There is little mention in literature of exhibitions as a marketing tool, or as a theoretical marketing concept, in the context of marketing or strategy. There is no detailed classification of or extensive theoretical debate around the concept. Exhibitions are mainly discussed in terms of their benefits (Allwood \& Montgomery, 1989; Brassington \& Pettitt, 1997; Weisgal, 1997). Kotler (2000) only devotes four sentences to exhibitions as a promotional tool; Churchill and Peter (1998) not much more.

The following favourable contributions and functions of exhibitions are mentioned: product launch and demonstration; marketing and business window; interactive two-way communication; learning and training experience; generation of leads; relationship building; market presence and enhancing corporate image. It is deemed that there is still much scope for improvement regarding the awareness, utilisation and understanding of the medium in this country.

\section{Objective}

The objective of the research is to evaluate the use of the exhibition medium as a component of a company's marketing effort, and its perceived effectiveness as a marketing tool. This is done by comparing exhibitions with other marketing tools and determining to what extent a company adopts an integrative approach to its marketing initiatives. The exercise is seen as an exploratory study in the South African market.

\section{Approach}

A total of 107 companies were taken as a sample of actual and potential exhibition users, representing a cross-section of industry. The sample was chosen from leading sectors in industry, including manufacturing, mining, building and construction. This group represents some $45 \%$ of South Africa's Gross Domestic Product (Business Monitor International, 1998).

A questionnaire was e-mailed and faxed to the sales manager, marketing manager, managing director or general manager of the organisation. The focus of the questions was directed at issues such as the objectives of exhibition participation, effectiveness of the medium and the extent to which exhibitions are integrated with a company's marketing strategy (or mix).

In-depth interviews were also conducted with senior management of the 10 largest companies, to facilitate and promote information sharing. In addition, the 
questionnaire was discussed with three of South Africa's leading exhibition organisers.

\section{RESULTS}

The findings are restricted to issues relevant to the research objective, and serve to summarise the common denominators among participating companies.

The feedback represents both positive and negative issues. Findings are both quantitative and qualitative, not necessarily listed in order of importance below.

A total of 27 returns were received, in addition to the 10 companies that participated in the in-depth interviews. The questions in the in-depth interviews were similar to those of the structured questionnaire, and the responses are incorporated in the results accordingly.

Although the sample of respondents might seem on the small side, the results of this study do add to the body of knowledge, if one considers the lack of other published research in South Africa on this subject.

Bearing in mind that this was an exploratory research project and the sample size is relatively small, the results cannot be rigorously tested and findings do not reflect true percentage responses, but only the majority/minority opinions of respondents to statements in the questionnaire.

The positive findings of the survey are:

- The majority of respondents find that the medium is effective for doing business, and that the intensity of sales and generation of leads are higher in comparison to other marketing options. Conversely, they are of the opinion that they would only like to attend one or two major shows a year, rather than a plethora of small ineffective events.

- Supporters of the exhibition medium find it very useful to be able to interact with existing key customers, as well as meeting future clientele.

- Many regard exhibitions as the ideal environment to launch new equipment, products, services and technologies, and to display competitive advantages to a captive audience in a specific target market.

- The medium is very suitable for establishing and/or maintaining a corporate image in a specific industry.

- Less than $40 \%$ of the respondents indicated that exhibitions are important as a component in the integration of the marketing mix. 
- Several respondents appreciate that exhibitions reach a broader section of a particular market than the key decision-makers. This means that employees in lower positions can influence the type of products and technologies purchased, even though they do not make direct buying decisions. This in effect allows companies to share knowledge with its user base and expand the learning process within an industry.

- Exhibiting companies wishing to export products, find it a cost-effective way of penetrating offshore markets, that is, being able to exhibit their products in a targeted country. The medium facilitates agency agreements, joint ventures, and licensing arrangements in both domestic and international markets.

The negative feedback from respondents points to a need to educate the market about the potential of the medium and its advantages over other marketing media.

- Respondents regard exhibition participation as an extremely costly exercise compared to other options in the marketing mix. These costs comprise not only the direct cost of participation, such as space costs, stand design, promotional material and exhibit transport, but also indirect cost in terms of staffing, and resources.

- Because the revenue generated does not match the perceived and actual expenditure of participation, respondents question the return on investment.

- Exhibitors find it very difficult to objectively measure the impact of the medium, claiming that they are unable to determine the effectiveness of a show. It is therefore uncertain what the medium actually yields. This highlights the need for a comparative system of measuring yields (or benefits) of exhibitions as against other marketing options.

- Certain exhibitors feel that they are compelled to participate in an event, merely because they would otherwise lose out in the face of competition -. not because they have any real wish to do so.

- Companies that provide services find exhibitions unsuitable for marketing them, while tangible products can be clearly displayed and demonstrated. Respondents perceive that an intangible product or service is not suited to the medium.

- Exhibitions in South Africa are costly, as they account for more than $13 \%$ of the average budget and are second only to print advertising.

- There is general concern that the exhibition medium has become highly fragmented and that there are simply too many shows, making excessive demands on limited marketing budgets. Exhibitors feel that exhibition organisers should get together with the object of regulating the medium and enhancing its effectiveness. 
- Some companies feel that South African exhibitions on the whole, do not match the scale and significance of their international counterparts, particularly those in Europe. This seems to suggest that key decision-makers in the local market would rather attend specific industry events in other parts of the world.

\section{Organisers}

Apart from respondent analysis, a perspective of providers of the exhibition medium is given too. The feedback of leading South African, and effectively southern African, exhibition organisers is typical of the current status of the industry and the perceived role that it plays in the marketing mix in this region.

- Leading organisers perceive that many exhibiting companies make poor exhibition choices, which taint the medium amongst both exhibitors and the public. They emphasise that it is essential for exhibiting companies or potential exhibitors, to carefully select high quality, industry-focused exhibits that will deliver an effective return on investment. Detailed analysis of these considerations falls outside the scope of this paper, but it is essential, as with any other business, that the right marketing channel is selected.

- According to organisers, exhibitors do not set clear objectives for participation and are therefore uncertain, particularly about what they hope to achieve. Linked to the lack of clear objectives, is the fact that it is particularly difficult to objectively measure results, without any means of comparing their respective effects.

- It often seems that marketing and sales teams are at opposite ends of the exhibition decision. "Marketing" buys into the concept and sets about delivering a result, while "sales" is opposed to the concept from the start and perceives it as a waste of time. Exhibition organisers feel that this problem condemns an exhibition campaign even before it has started.

- Organisers are also concerned about inadequate training of the staff manning stands, and employing the wrong kind of stand personnel. According to organisers, a company's most senior and competent personnel should be involved in selecting personnel to promote the image of the firm to the best advantage.

- Exhibition organisers are concerned that exhibiting companies do not integrate other aspects of marketing, to make their campaigns more effective and realise the full potential of the medium. The organisers therefore support a more cohesive and coordinated approach to exhibition participation in general.

- Exhibition organising companies regard the medium as unique, and with great advantages over other marketing options. They do acknowledge, however, that they can and should do more to promote and develop the medium in South Africa. 
- Organisers criticise the lack of government support of and involvement in the use of the medium. In many international markets, governments fund exhibition venues because of the great benefit gained for local and national economies in the form of airline travel, accommodation, business tourism and entertainment. Governments fund exporting companies through generous financial assistance for exhibition participation. While the matter has to some extent been addressed by the Department of Trade and Industry, the South African government does not support exhibition venues, apart from limited local metropolitan or council support, for example the International Convention Centre in Durban.

- Organisers also question the role of advertising agencies in the promotion and development of the medium. In this country, they are inclined to avoid recommending the medium to clients, because they receive no direct financial incentive to do so. Even though international agencies also do not receive media commissions, they recognise the benefit they receive in additional design revenue, consultation fees and media placements.

These often divergent qualitative findings, obtained from surveying both exhibiting companies and exhibition organising companies, emphasise the need to work towards a common goal of realising the full benefit of a more integrated approach to the exhibition medium as a tool of the overall marketing strategy of business enterprises in South Africa.

\section{Managerial Implications}

This study provides insight into the value and perceived role of the exhibition medium within the broader business marketing communications mix. Local publications carry articles on aspects of the medium and the industry, often on an superficial level. Exhibition organisers do however conduct research which helps businesses develop objectives by profiling exhibitor and visitor feedback on the performance of a particular event or exhibition

The most important issues that emerge from the study are the following:

- The exhibition medium has grown in stature over the last five years and enjoys a higher level of awareness in the marketing and business community in South Africa than before.

- Local and international research show that the exhibition medium offers a unique means of profiling company image and exposing products and services and generally providing a powerful means of advertising and promotion.

- Although it has been proven that the medium improves sales, it should be viewed in terms of long-term returns. Exhibitions seem to benefit products rather than services.

- Because it is so difficult to measure the benefits of exhibitions, exhibitors 
question their potential value. Organisers argue that poor preparation and organisation by certain exhibitors have a detrimental effect on the value of exhibitions.

- Certain exhibiting companies also question the return on investment that exhibitions offer. This however remains a value judgement, as there is no formal procedure or formula that can determine returns accurately. Future research should address this problem.

- Other components of the marketing mix should be integrated with the exhibition medium, in order to realise the full potential of and achieve the optimum effect for the exhibitor.

- This research shows that exhibitions in South Africa represent $13.4 \%$ of the average marketing budget of a business, which makes them the second most expensive means of advertising. Local exhibition organisers were surprised by these statistics, as they had previously believed that exhibitions received a disproportionately lower percentage of the typical marketing budget of their international counterparts.

\section{FUTURE RESEARCH}

The limitations of the present study at least serve as a useful basis for recommending future research.

- In the first place, the size of the research sample could be increased and allow for replication of this exercise to determine the consistency of trends.

- Such replication could also be related to specific exhibitions in specific industries, to establish normative standards in various sectors of the economy, rather than assume averages.

- The sample population in this study has been limited to established users of the medium. Research addressing the perceptions and attitudes of local nonusers could also prove valuable and interesting.

- Research should be done in the measurement of the medium, possibly with a view to developing an industry standard or model. Such research should take into account measurability in terms of effectiveness as well as return on investment.

- This study has focused on exhibitions as a business-to-business medium. This does not take into account broad-based events or consumer shows, and research in this area would probably reveal a different set of data and findings.

- The integration of technology, information, communication and entertainment is a broad and challenging one. The impact on the exhibition industry could prove valuable. 
- In a sense, the research conducted has been static and not incorporated the effect of technological progress. Given the extent of technological impact on most industries, local research on an issue that is being probed globally should prove valuable, here too.

- The formation of a marketing strategy, integrating components of the marketing mix, could help to improve the understanding of problems and limitations that marketers encounter when considering exhibitions.

- The value of the medium as a sales tool through the stages of a product's life cycle, is a further recommendation. This would help to measure the effectiveness of the medium in the generation of direct sales.

- Although it would also be rather detailed, research regarding the marketing of services would prove valuable in measuring the effectiveness of the medium.

\section{CONCLUSION}

Where do exhibitions fit in? An exhibition is a combination of direct selling and advertising. Sales personnel man a stand in order to generate business and the stand itself is designed to create awareness, explain and demonstrate a product or service, and to answer market questions. In essence, exhibitions can and do play a cost-effective role in the marketing mix, across the complete life cycle of a product.

Notwithstanding the limitations identified and the considerable recommendations for further research, this research project has shown that exhibitions have a definite role to play in the South African marketing. It has helped to understand. assess and improve this product in profiling South African businesses.

\section{REFERENCES}

1 ALLWOOD, J. and MONTGOMERY, H. (1989) Exhibition Planning and Design: A Guide for Exhibitors, Designers and Contractors. London: Batsford.

2 BRASSINGTON, F. and PETTITT, S. (1997) Principles of Marketing, London: Pitman Publishing: 812-17.

3 BUSINESS MONITOR INTERNATIONAL (1998) South Africa 1998: Annual report on Government, Economy, the Business Environment, Capital Markets and Industry. June: 119-46.

4 CHURCHILL, G. A. and PETER, J. P. (1998) Marketing: Creating Value for Customers, $2^{\text {nd }}$ ed. Boston, Massachusetts: Irwin McGraw-Hill: 490. 
5 DE WET, K, (1997) "Global Approach Set to Propel Local Exhibition Industry." Southern African PR Journal, February: 16-19.

6 Finance Week, 1999 PriceWaterhouseCoopers Survey. September: 8-9.

7 KOTLER, P. (2000) Marketing Management. The Millenium Edition, New Jersey: Prentice Hall: 603.

8 SCHUTTE, J and JACK, M. (1997) "Primedia: Lights, Camera, Action!" South African Media/Entertainment Research. Merril Lynch. December.

9 WEISGAL, M.B. (1997) Show and Sell: 133 Business Building Ways to Promote Your Trade Show Exhibit. New York: Amacom. 